\title{
Experimental Study on Reinforced Concrete Column Incased in Prefabricated Permanent Thin-Walled Steel Form
}

\author{
Jae Yuel Oh, ${ }^{1}$ Deuck Hang Lee, ${ }^{2}$ Jungmin Lee, ${ }^{1}$ Kang Su Kim, ${ }^{1}$ and Sung-Bae Kim ${ }^{3}$ \\ ${ }^{1}$ Department of Architectural Engineering, University of Seoul, 163 Seoulsiripdae-ro, Dongdaemun-gu, Seoul 02504, Republic of Korea \\ ${ }^{2}$ Department of Civil and Environmental Engineering, University of Illinois at Urbana-Champaign, 205 N. Mathews Ave., \\ Urbana, IL 61801, USA \\ ${ }^{3}$ Department of Structural Design, The Naeun Structural Engineering, 22 Yangpyeong-ro, Yeongdeungpo-gu, \\ Seoul 07205, Republic of Korea
}

Correspondence should be addressed to Kang Su Kim; kangkim@uos.ac.kr

Received 16 June 2016; Revised 4 August 2016; Accepted 7 August 2016

Academic Editor: Ana S. Guimarães

Copyright (C) 2016 Jae Yuel Oh et al. This is an open access article distributed under the Creative Commons Attribution License, which permits unrestricted use, distribution, and reproduction in any medium, provided the original work is properly cited.

\begin{abstract}
Conventional construction methods of reinforced concrete (RC) structures generally require a long construction period and high costs due to many on-site temporary form works. In this study, a prefabricated permanent thin-walled steel form integrated with reinforcement cage (PPSFRC) was developed, and it makes for a fast-built construction by reducing the temporary form works. Axial compression tests were conducted on a total of 9 test specimens to investigate the structural performances of the newly developed columns. The proposed column construction method utilized relatively thinner steel plates compared to conventional concrete-filled tube (CFT) columns, but it was designed to have sufficient resistance performances against the lateral pressure of fresh concrete and to prevent the buckling of the thin plates by utilizing the steel angles and channel stiffeners prefabricated in the permanent thin-walled steel form. The experimental results showed that the column specimens fabricated by the PPSFRC method had better local buckling resistance and behaved in a more ductile manner compared to the conventional CFT columns. In addition, the axial strengths of the test specimens were compared with those estimated by design provisions, and the flexural moments induced by initial imperfection or accidental eccentricity of axial loads were also discussed in detail.
\end{abstract}

\section{Introduction}

Reinforced concrete (RC) structures have been widely used in constructions of buildings and infrastructures based on technology and know-how accumulated over the last several decades as well as excellent cost competitiveness of concrete material. However, recently with a sharp increase in labor costs, the on-site temporary works including concrete formworks require high costs in construction markets. Especially for the cases of bridge and building structures with high story heights, the construction time and costs for the temporary works have significantly increased, and thus the competitiveness of the RC construction method has been greatly fallen off [1-3]. In typical RC frame constructions, the construction process of columns is one of the critical paths, and it is, therefore, absolutely advantageous to minimize the on-site temporary works for reduction of the construction period. In this study, a prefabricated permanent steel form integrated with reinforcing cage (PPSFRC) was developed to overcome such problems inherent in the typical RC construction method, and the structural performance of the columns produced by utilizing the new fast-built construction method was also investigated.

Figure 1 shows the prefabricated permanent steel form integrated with reinforcing cage (PPSFRC) developed in this study according to the fabrication process. The thinwalled steel plate tube was reinforced by the multiple steel stiffener angles and channels in the longitudinal and transverse directions, and longitudinal reinforcements and shear reinforcements were also placed inside the permanent steel form. After the fabrication of a half part of steel cage, the longitudinal and transverse reinforcement were placed in the cage, and the multiple steel stiffener angles were then welded to the longitudinal channels in the longitudinal and 


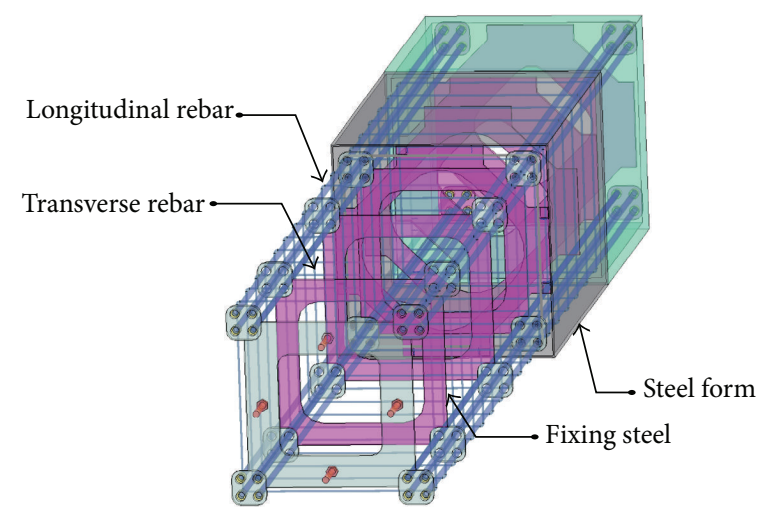

(a) Concept of proposed permanent steel form integrated with prefabricated reinforcement cage

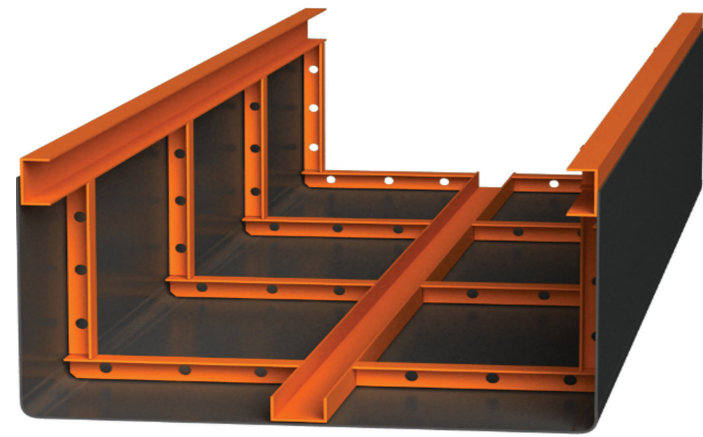

$\langle$ Fabrication of a half part of steel cage $\rangle$

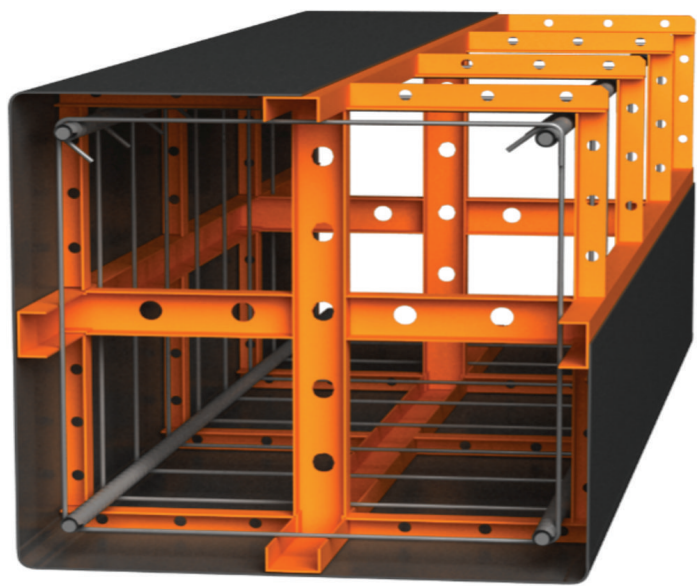

$\langle$ Covering a quarter of steel cage $\rangle$

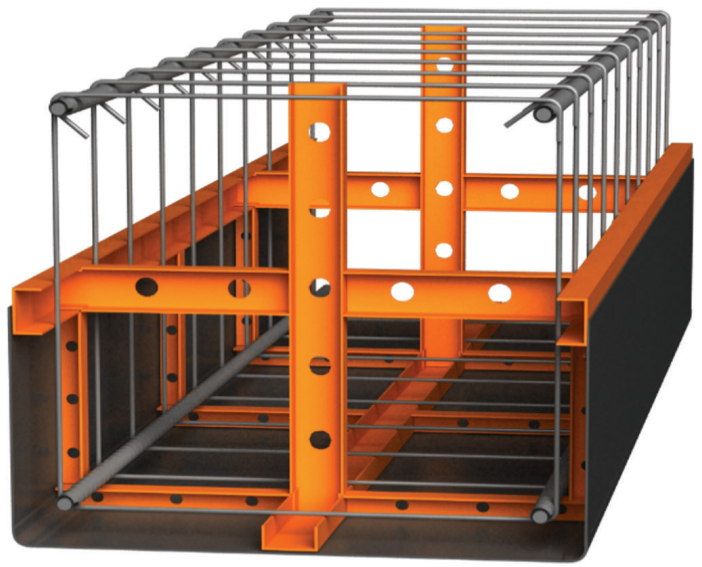

$\langle$ Arrangement of reinforcement and channels $\rangle$

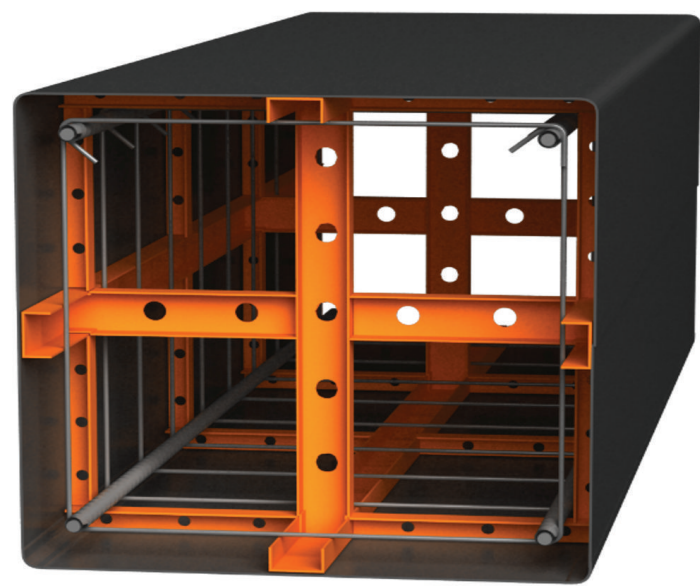

$\langle$ Completion of steel cage with reinforcement $\rangle$

(b) Fabrication process of proposed permanent steel form

FIGURE 1: Permanent thin-walled steel form integrated with prefabricated reinforcement cage.

transverse directions. Then, after a quarter of the steel cage was covered by welding it to the longitudinal channels, the last quarter of the steel cage was covered by welding it to the longitudinal channels as well. The thin-walled steel form was designed to prevent excessive deformations that can be possibly induced during the transportation and temporary works and by the lateral pressure of fresh concrete. Since the reinforcement cages are prefabricated inside the permanent steel form, the concrete can be cast right after installations of the steel form, and thus construction time can be significantly reduced. The permanent steel form has quite a thin thickness, and thus the strength contribution of the steel form on 
TABLE 1: Summary of test specimens.

\begin{tabular}{|c|c|c|c|c|c|}
\hline Number & Specimen & Compressive strength of concrete (MPa) & Steel form & Yield strength of reinforcing bars $(\mathrm{MPa})$ & Gap \\
\hline 1 & R21-S600 & 21 & $\mathrm{X}$ & 600 & $\mathrm{X}$ \\
\hline 2 & P21-S600 & 21 & $\mathrm{O}$ & 600 & $\mathrm{X}$ \\
\hline 3 & P21-S400 & 21 & $\mathrm{O}$ & 400 & $\mathrm{X}$ \\
\hline 4 & P21-S600G & 21 & $\mathrm{O}$ & 600 & $\mathrm{O}$ \\
\hline 5 & R30-S600 & 30 & $\mathrm{X}$ & 600 & $\mathrm{X}$ \\
\hline 6 & P30-S600 & 30 & $\mathrm{O}$ & 600 & $\mathrm{X}$ \\
\hline 7 & P30-S400 & 30 & $\mathrm{O}$ & 400 & $\mathrm{X}$ \\
\hline 8 & P30-S600G & 30 & $\mathrm{O}$ & 600 & $\mathrm{O}$ \\
\hline 9 & CFT & 21 & $\mathrm{X}$ & - & $\mathrm{X}$ \\
\hline
\end{tabular}

the column is neglected, and only the concrete and rebar placed inside the steel form are considered in the strength calculation just like a typical RC column. If the column with PPSFRC is considered as a composite member, the minimum steel area ratio $\left(A_{s, \min }\right)$ and the width-to-thickness ratio $\left((B\right.$ or $\left.D) / t_{\max }\right)$ should satisfy the design criteria required for steel-concrete composite columns. In the design of the columns with PPSFRC, however, the strength contribution of the steel form on the column strength is neglected, which means that the requirements of the minimum steel area ratio and width-to-thickness ratio can be neglected in their design. For this reason, an efficient design can be possible by employing very thin steel plates. The PPSFRC columns can also secure good fire resistance that is equal to or higher than that of conventional RC members, and thus no additional fire protection is required for their applications $[4,5]$.

\section{Experimental Program}

2.1. Test Specimens. In order to investigate the structural performances of the PPSFRC columns under axial loads, a total of nine specimens was fabricated, among which two specimens were conventional RC columns (R-series specimens), six specimens were PRSFRC columns (P-series specimens), and one specimen was concrete-filled tube column (CFT column). As summarized in Table 1, the types of column, the compressive strengths of concrete, and the strength grades of reinforcing bar were considered as the key test parameters, and, especially in the P21-S600G and P30-S400G specimens, $10 \mathrm{~mm}$ gaps were intentionally introduced between the steel form and the load-transfer plate on the top to prevent the local buckling (see Figure 2(b)) [6-9]. As shown in Figure 2, all the test specimens were $1480 \mathrm{~mm}$ in height and $350 \mathrm{~mm}$ in width $(B)$. The top and bottom of the test specimens were reinforced with the load-transfer steel plates with a thickness of $40 \mathrm{~mm}$ to avoid stress concentrations at loading points and to introduce uniformly distributed compressive stresses over the cross section of the test specimens. In addition, two stiffeners with $12 \mathrm{~mm}$ and $75 \mathrm{~mm}$ in thickness and length, respectively, were provided on each side of the top and bottom of the specimens to prevent the local buckling (see Figure 2(b)). For better workability of fresh concrete, a hole with a diameter of $150 \mathrm{~mm}$ was placed at the center of the top load-transfer plate, and four air-vent holes with a diameter of $30 \mathrm{~mm}$ were placed on each corner of the column specimen. The P-series specimens and the CFT specimen had a hole with a $20 \mathrm{~mm}$ in diameter at $300 \mathrm{~mm}$ away from the bottom face of the test specimens so that the concrete filling can be visually checked during the concrete casting. In the R-series and P-series specimens, four screw-ribbed reinforcing bars with a diameter of $25.4 \mathrm{~mm}$ were used in the longitudinal direction, and hoops with a diameter of $9.5 \mathrm{~mm}$ were provided at $150 \mathrm{~mm}$ spacing. The reason for the use of the screw-ribbed reinforcing bar with the large diameter is to facilitate simple mechanical splice connections of the longitudinal reinforcements [10]. In the steel plates of the P-series specimens, the steel tube was welded with groove in the longitudinal direction. C- $40 \times 25 \times 4$ steel channels were attached on four inner sides of the steel form in the longitudinal direction by fillet welding with $3 \mathrm{~mm}$ wide and $100 \mathrm{~mm}$ long at every $300 \mathrm{~mm}$ to prevent excessive deformations induced by the lateral pressure of fresh concrete, and L- $25 \times 25 \times 3.2$ steel angles were also placed at $600 \mathrm{~mm}$ spacing in the transverse direction and welded to the longitudinal channels using fillet welding with a width of $5 \mathrm{~mm}$.

Table 2 shows a summary of the current design code provisions related to CFT columns, specified in the American Institute of Steel Construction (AISC), Eurocode 4, and Korean Building Code (KBC) [11-13]. The revised KBC and AISC alleviated the limits of the width-to-thickness ratio $\left(B / t_{w}\right)$ and the minimum area ratio of a steel material $\left(A_{s, \min }\right)$ and expanded the application ranges of the material strengths of concrete and steel plates $\left(f_{c}^{\prime}\right.$ and $\left.F_{y, \max }\right)$. For the Pseries specimens and the CFT specimen tested in this study, $3.2 \mathrm{~mm}$ and $7.0 \mathrm{~mm}$ steel plates were used, respectively, and corresponding steel ratios $\left(A_{s} / A_{q}\right)$ were $3.6 \%$ and $7.0 \%$, respectively, which satisfy the minimum steel ratio $\left(A_{s, \min }\right)$ specified in the design provisions shown in Table 2. The width-to-thickness ratio $\left(B / t_{w}\right)$ of the CFT specimen was 50.0 , which was designed to meet the provisions specified in KBC, AISC, and Eurocode 4, whereas that of the P-series specimens was 109.0, which was intentionally designed not to satisfy the current design provisions. Since the main feature of the proposed method is to use thin-walled steel plates as the permanent steel form and not to account for its strength contribution in the structural design, the width-to-thickness 


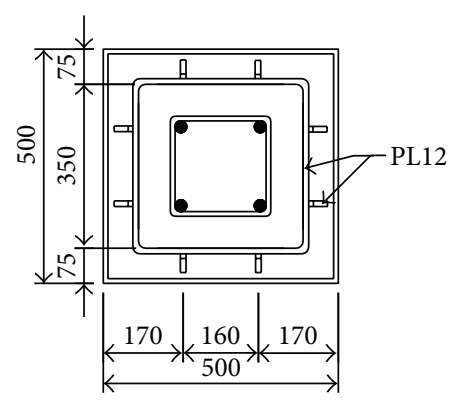

$\left\langle\mathrm{A}-\mathrm{A}^{\prime}\right.$ section $\rangle$

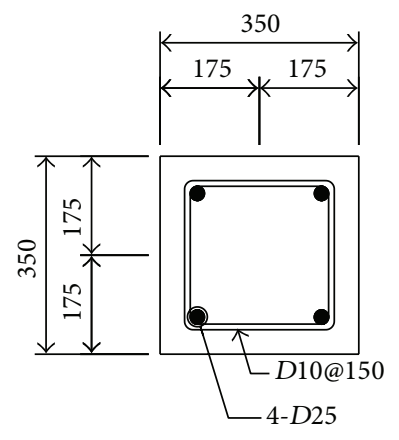

$\left\langle\mathrm{B}^{\mathrm{B}} \mathrm{B}^{\prime}\right.$ section $\rangle$

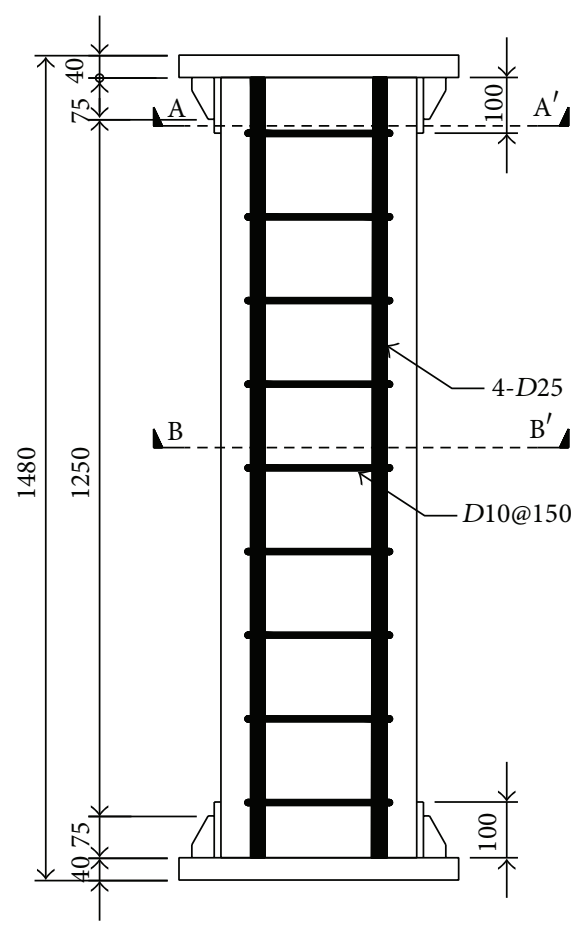

$\langle$ Elevation〉

(a) R series specimens

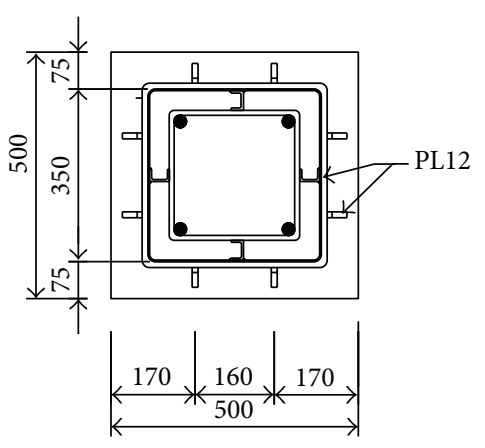

$\langle$ A-A' section〉

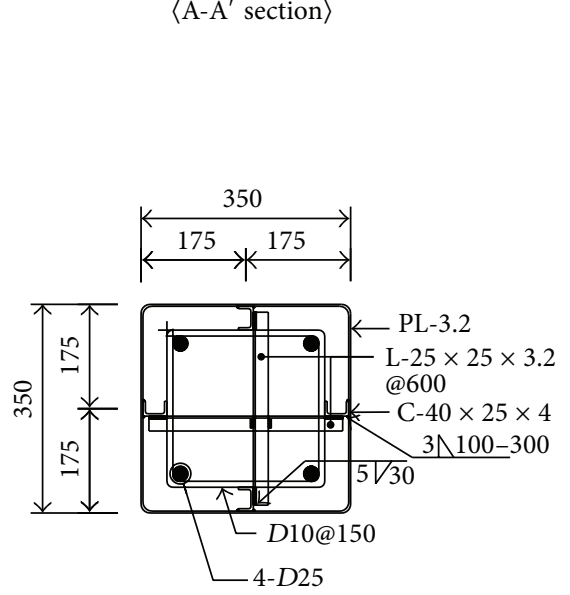

$\left\langle\mathrm{B}-\mathrm{B}^{\prime}\right.$ section $\rangle$

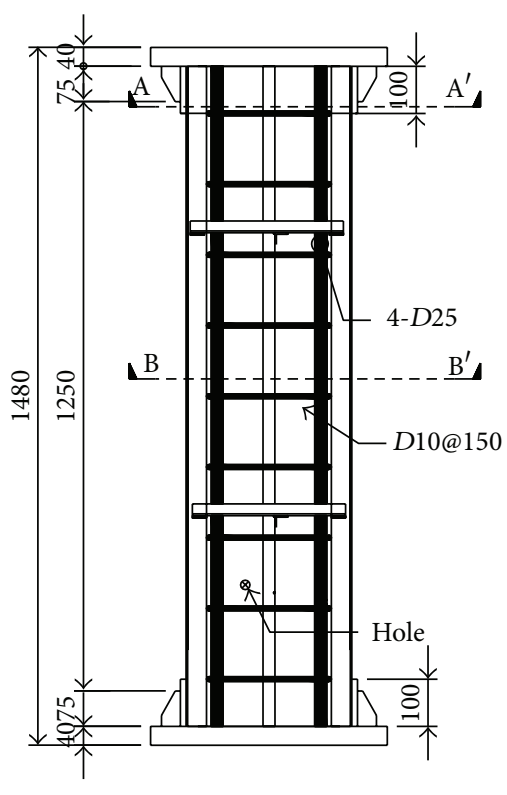

〈Elevation without gap〉

(b) P series specimens

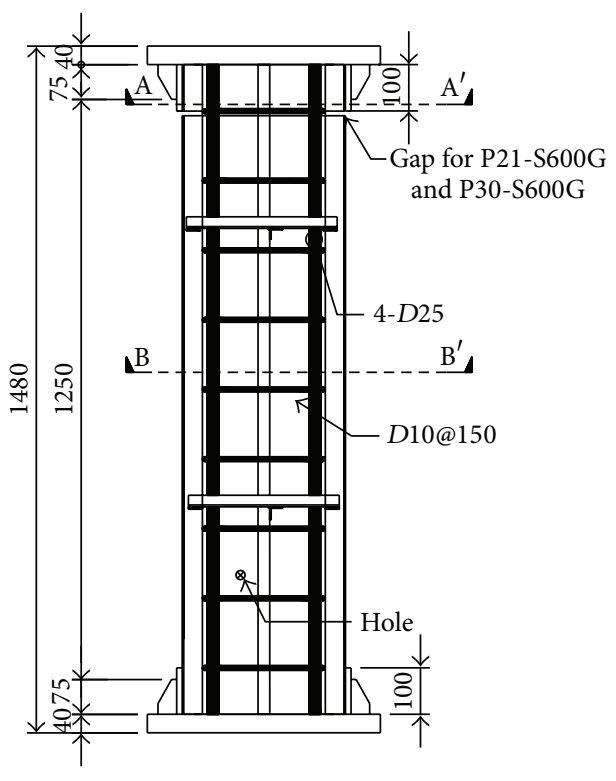

$\langle$ Elevation with gap〉

FIgUre 2: Continued. 


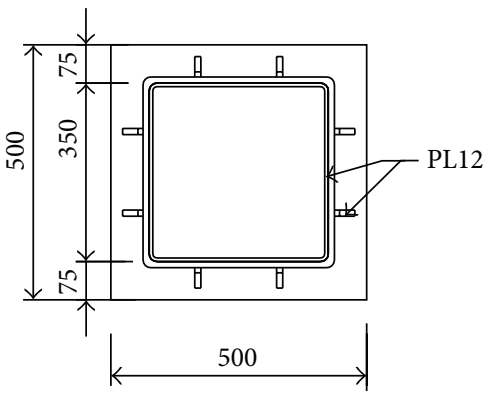

$\left\langle\mathrm{A}-\mathrm{A}^{\prime}\right.$ section $\rangle$

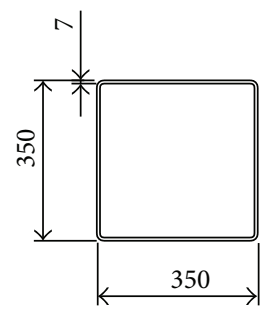

$\left\langle\mathrm{B}-\mathrm{B}^{\prime}\right.$ section $\rangle$

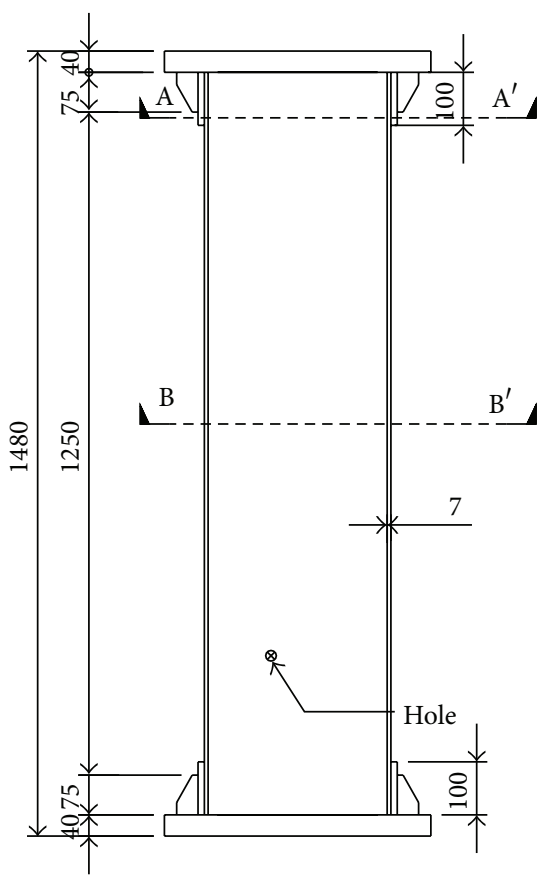

$\langle$ Elevation $\rangle$

(c) CFT specimen

Figure 2: Dimensional details of test specimens.

TABLE 2: Specifications regarding CFT in national design codes.

\begin{tabular}{|c|c|c|c|c|c|c|c|c|c|c|c|}
\hline \multirow{2}{*}{ Code } & \multicolumn{4}{|c|}{ KBC } & \multicolumn{4}{|c|}{ AISC } & \multirow{2}{*}{\multicolumn{3}{|c|}{ Eurocode 4}} \\
\hline & \multicolumn{2}{|c|}{2005} & \multicolumn{2}{|c|}{2009} & \multicolumn{2}{|c|}{1999} & \multicolumn{2}{|c|}{2005} & & & \\
\hline$A_{s} / A_{g}$ & \multicolumn{2}{|c|}{$3 \%$ or above } & \multicolumn{2}{|c|}{$1 \%$ or above } & \multicolumn{2}{|c|}{$4 \%$ or above } & \multicolumn{2}{|c|}{$1 \%$ or above } & \multicolumn{3}{|c|}{$2 \%-9 \%$} \\
\hline$f_{c}^{\prime}$ & \multicolumn{2}{|c|}{$20.5 \mathrm{MPa}$ or greater } & \multicolumn{2}{|c|}{$21-70 \mathrm{MPa}$} & \multicolumn{2}{|c|}{$21-55 \mathrm{MPa}$} & \multicolumn{2}{|c|}{$21-70 \mathrm{MPa}$} & \multicolumn{3}{|c|}{ 20-50 MPa } \\
\hline$F_{y, \max }$ & \multicolumn{2}{|c|}{$415 \mathrm{MPa}$} & \multicolumn{2}{|c|}{$440 \mathrm{MPa}$} & \multicolumn{2}{|c|}{$415 \mathrm{MPa}$} & \multicolumn{2}{|c|}{$440 \mathrm{MPa}$} & \multicolumn{3}{|c|}{$450 \mathrm{MPa}$} \\
\hline Shape & $\square$ & O & $\square$ & O & $\square$ & 0 & $\square$ & O & & $\square$ & O \\
\hline$(B$ or $D) / t_{w}$ & $\sqrt{\frac{3 E}{F_{y}}}$ & $\sqrt{\frac{8 E}{F_{y}}}$ & $\sqrt{\frac{5.1 E}{F_{y}}}$ & $\frac{0.15 E}{F_{y}}$ & $\sqrt{\frac{3 E}{F_{y}}}$ & $\sqrt{\frac{8 E}{F_{y}}}$ & $\sqrt{\frac{5.1 E}{F_{y}}}$ & $\frac{0.15 E}{F_{y}}$ & $52 \sqrt{3}$ & $\sqrt{\frac{235}{F_{y}}}$ & $90 \frac{235}{F_{y}}$ \\
\hline
\end{tabular}

ratio $\left(B / t_{w}\right)$ was, therefore, intentionally increased for the Pseries specimens.

2.2. Material Properties. The concrete mix proportions used in the test specimens are summarized in Table 3. The design compressive strengths were $21.0 \mathrm{MPa}$ and $30.0 \mathrm{MPa}$, respectively, and those obtained from material tests were 26.3 $\mathrm{MPa}$ and 44.2 $\mathrm{MPa}$, respectively. The yield strengths of SD400 and SD600 threaded bars with a diameter of $25.0 \mathrm{~mm}$ were measured as $460 \mathrm{MPa}$ and $690 \mathrm{MPa}$, respectively. For the P-series specimens and the CFT specimen, grade SS400 steel plates with $3.2 \mathrm{~mm}$ and $7.0 \mathrm{~mm}$ in thickness were used, respectively, and their yield strengths obtained from material tests were $350 \mathrm{MPa}$ and $388 \mathrm{MPa}$, respectively, as summarized in Table 4. As shown in Figure 3, the universal testing

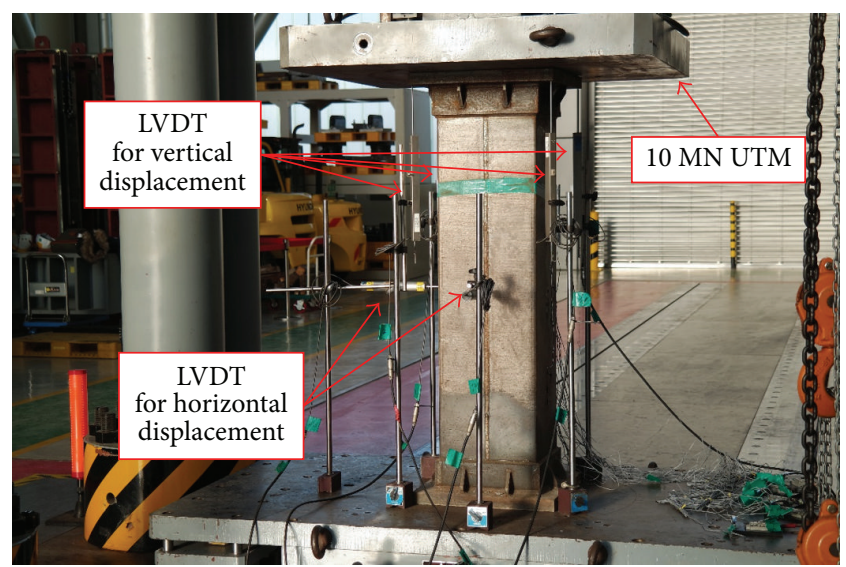

FIgURE 3: Test setup and measurement devices. 
TABLE 3: Concrete mix proportion.

\begin{tabular}{|c|c|c|c|c|c|c|c|c|}
\hline \multirow{2}{*}{ Design strength $(\mathrm{MPa})$} & \multirow{2}{*}{$G_{\max }(\mathrm{mm})$} & \multirow{2}{*}{$W / C(\%)$} & \multirow{2}{*}{$S / A(\%)$} & \multicolumn{5}{|c|}{ Unit volume weight $\left(\mathrm{kg} / \mathrm{m}^{3}\right)$} \\
\hline & & & & $W$ & C & $S$ & G & $A D_{2}$ \\
\hline 21 & 25 & 56.1 & 48.8 & 179 & 319 & 856 & 915 & 1.60 \\
\hline 30 & 25 & 42.1 & 46.9 & 120 & 284 & 844 & 974 & 3.25 \\
\hline
\end{tabular}

TABLE 4: Material properties of concrete, rebars, and steel plates.

\begin{tabular}{lccccccccccc}
\hline \multirow{2}{*}{ Type } & \multicolumn{2}{c}{ Concrete } & \multicolumn{3}{c}{ Rebar } & \multicolumn{3}{c}{ Steel plate } \\
& $21 \mathrm{MPa}$ & \multirow{2}{*}{$30 \mathrm{MPa}$} & \multicolumn{2}{c}{$400 \mathrm{MPa}$} & & \multicolumn{2}{c}{$600 \mathrm{MPa}$} & \multicolumn{3}{c}{$3.2 \mathrm{~mm}$} & \multicolumn{2}{c}{$7 \mathrm{~mm}$} \\
& & & Yield & Ultimate & Yield & Ultimate & Yield & Ultimate & Yield & Ultimate \\
\hline Strength $(\mathrm{MPa})$ & 26.3 & 44.2 & 463 & 596.6 & 691.8 & 847.0 & 344.1 & 423.9 & 367.5 & 411.1 \\
\hline
\end{tabular}

machine of 10.0 MN capacity was used to apply axial loads on the column specimens with a constant loading rate of $0.02 \mathrm{~mm} / \mathrm{sec}$. In order to measure the vertical displacements of the specimens during testing, linear variable differential transformers (LVDTs) were installed on four corners of each specimen, and two LVDTs were additionally installed on two sides to measure the lateral displacements.

2.3. Test Results. Figures 4(a) and 4(b) show the axial loaddeformation responses of the test specimens with the design compressive strengths of $21.0 \mathrm{MPa}$ and $30 \mathrm{MPa}$, respectively. The average values of the axial displacements measured from the four LVDTs were used for the axial deformation, and the loading was terminated when reduced to $80.0 \%$ of the maximum load. The R21-S600 and R30-S600 specimens were conventional RC column specimens without the external steel form. Their maximum loads were $3,042 \mathrm{kN}$ and $3,782 \mathrm{kN}$, respectively, and the maximum displacements were $7.9 \mathrm{~mm}$ and $6.8 \mathrm{~mm}$, respectively.

As shown in Figure 5(a), the stiffness of the P21-S600 specimen slightly reduced at a load of about $3,000 \mathrm{kN}$ due to the initiation of local buckling, which was observed at the section by $B / 2(175 \mathrm{~mm})$ away from the top of the column specimen, and then the local buckling was gradually propagated downwards. As shown in Figure 5(b), at the maximum load of about $5,396 \mathrm{kN}$, the local buckling occurred at a spacing of about $300 \mathrm{~mm}$, which was almost equal to the spacing of the transverse steel stiffener channels. After the maximum load, a heavy local buckling occurred in the upper part of the column as shown in Figure 5(c), and the displacement reached $29.4 \mathrm{~mm}$ at final stage as shown in Figure 5(d). Other P-series specimens showed similar behavioral characteristics to the P21-S600 specimen. The P21S600G and P30-S600G specimens with $10 \mathrm{~mm}$ gap between the steel form and the load-transfer steel plate on the top of the column showed the same axial stiffness with the RC specimens (R21-S600 and R30-S600 specimens) as shown in Figures 4(a) and 4(b), respectively, which is because the axial load was transferred only through the concrete due to the gap of the steel form during the initial loading stage. As the applied load increased, the gap was gradually reduced and eventually closed, and then their behavior appeared to be very similar to those of the specimens P21-S600 and P30-S600. According to Johansson and Gylltoft [6], the concrete-filled composite columns with gaps between load-transfer plate and circular steel tube showed more ductile behavior compared to the one without gap. This is because when the steel plate without the gap was used, local tensile deformation occurred due to the confinement effect of the circular steel tube and led to the yielding or local buckling of the steel plates near the connection between the load-transfer plate and the steel form that occurred earlier than those without the gap. In this study, however, it was not observed because the confinement effect was relatively small due to the use of the thin steel plates with rectangular shaped sections.

In the case of the CFT specimen, the axial loads increased with a constant initial stiffness, and the stiffness decreased gradually just before the local buckling, which was observed at the section by $B / 2$ away from the top end of the column at a load of about $4,500 \mathrm{kN}$. At the ultimate load of $4,700 \mathrm{kN}$ with the maximum displacement of $12.0 \mathrm{~mm}$, a compressive failure occurred with heavy local buckling. Compared to the P-series specimens, the CFT specimen showed a very low deformation capability as shown in Figure 4(a), which can be inferred from the failure patterns shown in Figure 6. As shown in Figure 6(b), in the case of the P-series specimens except the P21-S600G and P30-S600G specimens, relatively small local buckling was distributed rather than being concentrated at a section due to the steel stiffener angles provided inside the column specimens.

As shown in Figure 6(c), in the case of the P21-S600G specimen, which had a $10 \mathrm{~mm}$ gap on the top of the steel tube, the local buckling was delayed by the gap, and the specimen had a convex radial deformation over a wide region of the steel tube before closing of the gap because of the Poisson strains of the concrete. Then, after closing of the gap, small local buckling concentrated at the top and middle of the column length occurred. The P30-S600G specimen, which also had a $10 \mathrm{~mm}$ gap on the top of the steel tube, had a very similar buckling behavior to the P21-S600G specimen. On the other hand, in the CFT specimen, as shown in Figure 6(d), the local buckling was concentrated at the section by $B / 2$ from the top of the column, and thus the deformation capability of the CFT column was relatively low compared to the P-series specimens. 


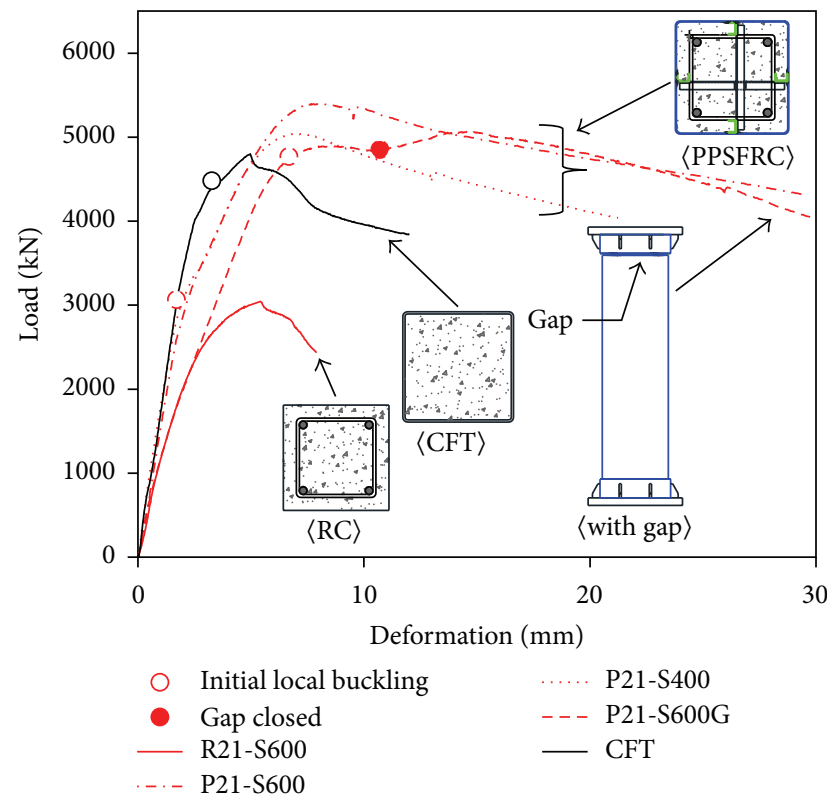

(a) R21 and P21 series specimens

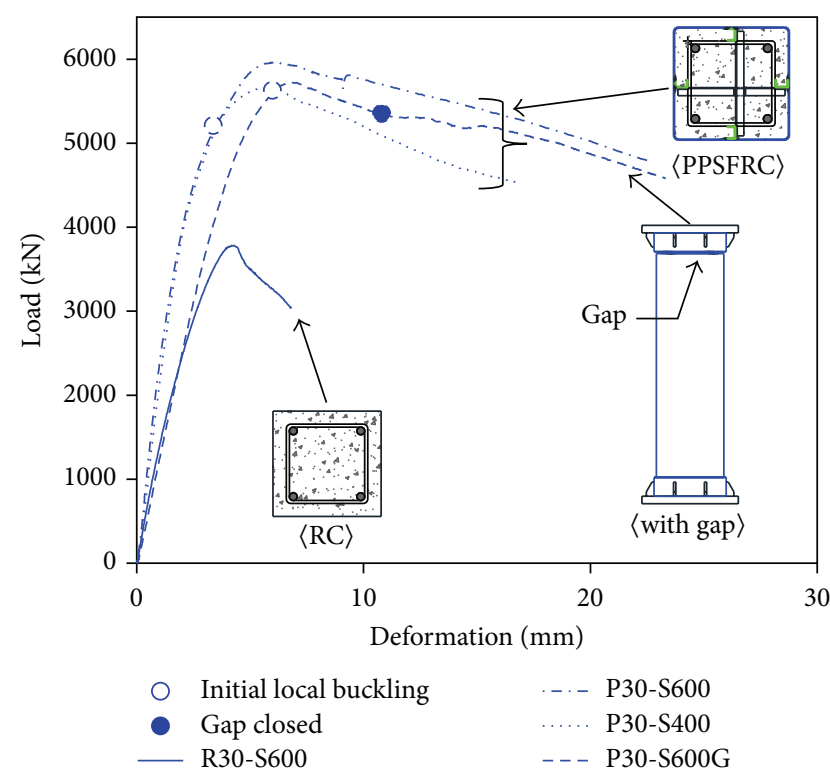

(b) R30 and P30 series specimens

FIGURE 4: Axial load-deformation responses of test specimens.

TABLE 5: Comparison of test results and calculated strengths.

\begin{tabular}{|c|c|c|c|c|c|c|c|c|c|c|c|}
\hline Number & Specimen & $P_{u}(\mathrm{kN})$ & $P_{0}(\mathrm{kN})$ & $P_{n}(\mathrm{kN})$ & $e_{m}(\mathrm{~mm})$ & $e_{i}(\mathrm{~mm})$ & $e_{\text {tot }}(\mathrm{mm})$ & $P_{e}(\mathrm{kN})$ & $P_{u} / P_{0}$ & $P_{u} / P_{n}$ & $\overline{P_{u} / P_{e}}$ \\
\hline 1 & $\mathrm{R} 21-\mathrm{S} 600$ & 3,042 & 4,011 & 3,209 & 13 & 7 & 20 & 3,354 & 0.76 & 0.95 & 0.91 \\
\hline 2 & P21-S600 & 5,396 & 5,748 & 3,109 & 7 & 7 & 14 & 4,895 & 0.94 & 1.74 & 1.10 \\
\hline 3 & $\mathrm{P} 21-\mathrm{S} 400$ & 5,041 & 5,282 & 2,736 & 7 & 7 & 14 & 4,895 & 0.95 & 1.84 & 1.03 \\
\hline 4 & P21-S600G & 5,062 & 5,748 & 3,109 & 20 & 7 & 27 & 4,507 & 0.88 & 1.63 & 1.12 \\
\hline 5 & R30-S600 & 3,782 & 5,789 & 4,631 & 16 & 7 & 23 & 5,313 & 0.65 & 0.82 & 0.71 \\
\hline 6 & P30-S600 & 5,964 & 7,571 & 4,567 & 20 & 7 & 27 & 6,185 & 0.79 & 1.31 & 0.96 \\
\hline 7 & P30-S400 & 5,660 & 7,104 & 4,194 & 18 & 7 & 25 & 6,138 & 0.80 & 1.35 & 0.92 \\
\hline 8 & P30-S600G & 5,721 & 7,571 & 4,567 & 26 & 7 & 33 & 5,864 & 0.76 & 1.25 & 0.98 \\
\hline 9 & CFT & 4,797 & 6,250 & 5,000 & 27 & 7 & 34 & 4,933 & 0.77 & 0.96 & 0.97 \\
\hline \multicolumn{9}{|c|}{ Average } & 0.81 & 1.32 & 0.97 \\
\hline
\end{tabular}

\section{Analytical Study}

The ACI318-14 presents the axial capacity estimation equation of RC columns based on 567 column test results conducted at the University of Illinois and Leigh University from 1927 to 1933 [14], as follows:

$$
P_{0}=f_{y} A_{s t}+\left(0.85 f_{c}^{\prime}\right)\left(A_{g}-A_{s}\right),
$$

where $f_{y}$ and $A_{s t}$ are the yield strength and the sectional area of reinforcements, respectively, and $f_{c}^{\prime}$ and $A_{g}$ are the compressive strength and the gross sectional area of concrete, respectively. Figure 7 and Table 5 show the comparison between the axial strengths calculated by $(1)\left(P_{o}\right)$ and those measured through the experiments $\left(P_{u}\right)$. The ratios of the axial strengths of the test specimens to those estimated by (1) $\left(P_{u} / P_{o}\right)$ were distributed between 0.65 and 0.95 , which indicates that the axial capacities estimated by (1) overestimate the test results. This would be most likely because the initial imperfection $\left(e_{i}\right)$ inevitably occurring during the production process and the minimum accidental eccentricity $\left(e_{m}\right)$ caused by the test setup of the specimen were not taken into consideration. For this reason, ACI318-14 [14] adopted a factor of 0.8 for RC columns with rectangular cross sections. In this study, the eccentricity induced by the initial imperfection $\left(e_{i}\right)$ was assumed to be $L / 200$ as presented in Eurocode 4 [12]. Since the length of the column specimens tested in this study was $1400 \mathrm{~mm}$, the initial imperfection $\left(e_{i}\right)$ of the specimens was estimated to be $7.0 \mathrm{~mm}$. In addition, the minimum accidental eccentricity $\left(e_{m}\right)$ that could possibly occur when axial load was applied to the column specimens needs to be considered to analyze the test results. As shown in Figure 8, the eccentricity of the loading causes bending moment, and the rotation angle $(\theta)$ caused by the bending moment can be calculated, as follows:

$$
\tan \theta \approx \theta=\frac{L}{D}
$$




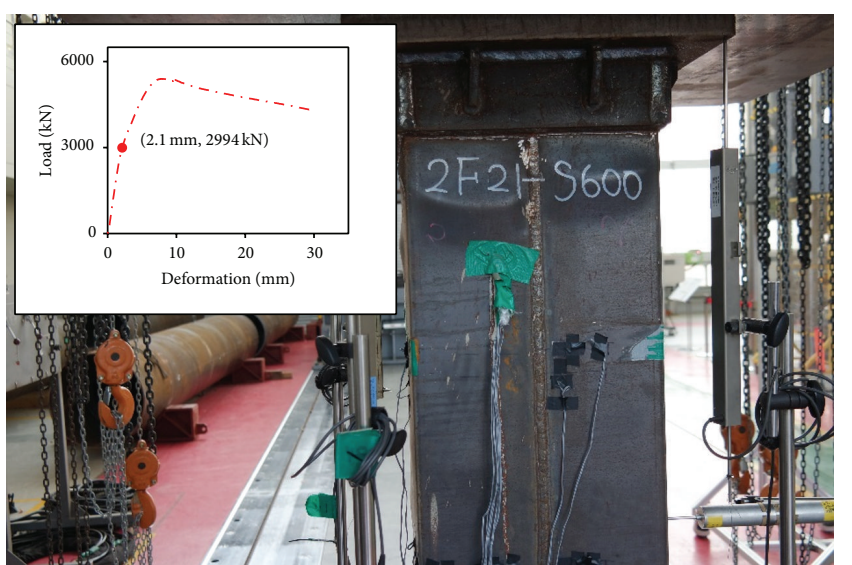

(a) Initial buckling stage

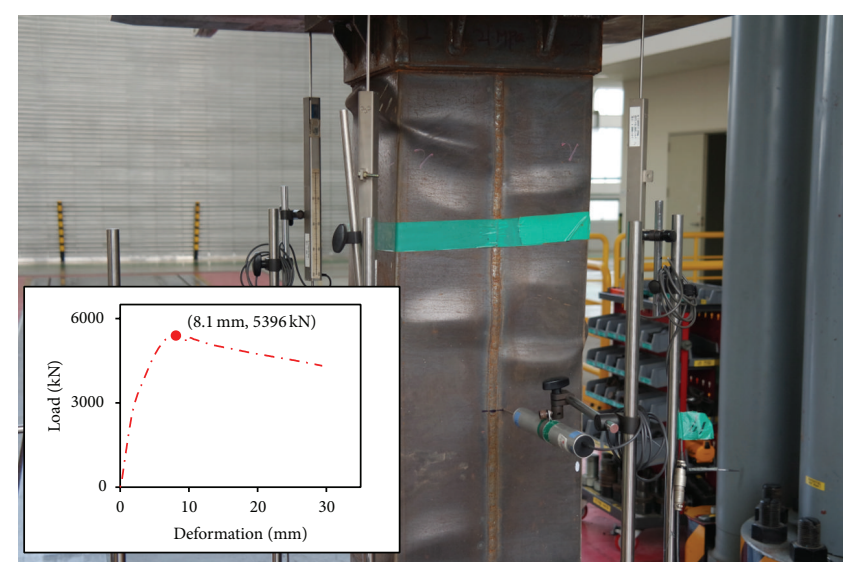

(b) Maximum load stage

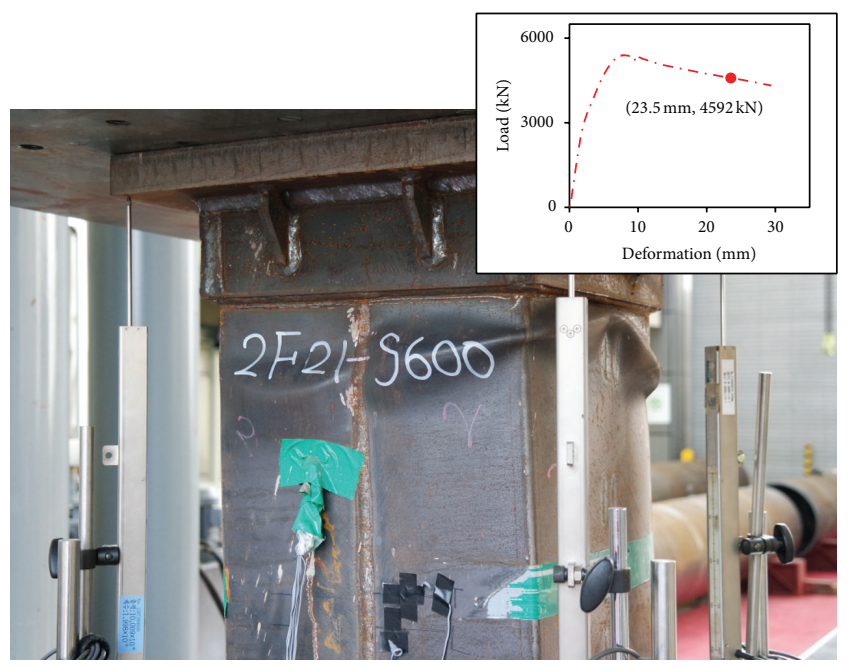

(c) Postpeak stage

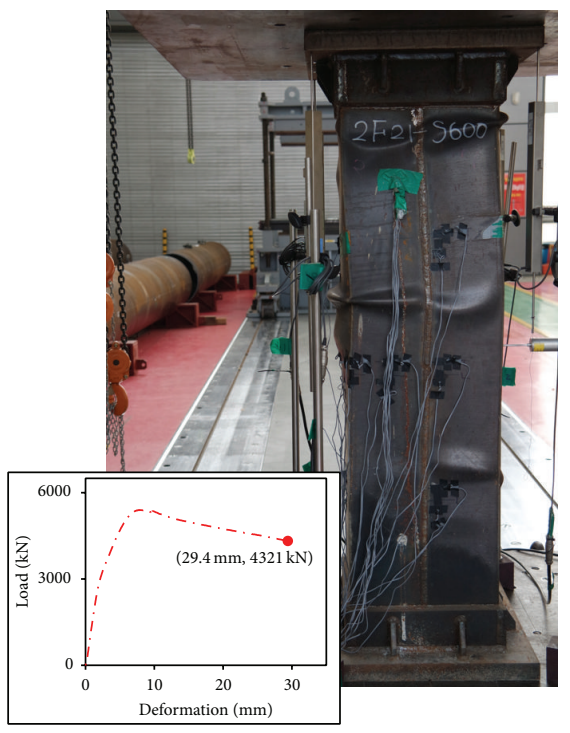

(d) Final stage

FIgURE 5: Detailed behavioral characteristics of P21-S600 specimen.

where $L$ is taken to be $B / 2$ and $D$ is the axial deformation at the extreme fiber of the cross section, which was measured from the LVDTs installed during the all loading stages. If the bending moment was constant along the member axis, the relationship between the rotation angle of the member $(\theta)$ and the bending moment $(M)$ can be expressed, as follows:

$$
M=\theta \frac{E I}{l},
$$

where $E$ and $I$ are the modulus of elasticity and the moment of inertia. As aforementioned, although the columns with PPSFRC are not considered as composite members for the design, the reinforcing bars and steel plates need to be considered for the calculation of $E$ and $I$ in (3) that are needed to estimate the minimum accidental eccentricity $\left(e_{m}\right)$, which was done by the transformed section method [15]. The bending moment $(M)$ can be estimated by substituting the measured rotation angle $(\theta)$ into (3), and the magnitude of eccentricity $\left(e_{m}\right)$ can be calculated, as follows:

$$
e_{m}=\frac{M}{P}
$$

As summarized in Table 5, the minimum accidental eccentricities $\left(e_{m}\right)$ of the specimens estimated from (4) were distributed between $7.0 \mathrm{~mm}$ and $27.0 \mathrm{~mm}$. Considering the eccentricity $\left(e_{m}\right)$ of axial loads and the initial imperfection $\left(e_{i}\right)$, the estimated total eccentricities $\left(e_{\text {tot }}\right)$ of the test specimens can be estimated, which were ranged from $14.0 \mathrm{~mm}$ to $34.0 \mathrm{~mm}$. Accordingly, as shown in Figure 9(a), the axial strength $\left(P_{o}\right)$ was reduced to $P_{e}$ by considering the effect of the eccentricity $\left(e_{\text {tot }}\right)$, and Figure 9(b) shows the analysis results of the P21-S600 specimen considering the influence of the eccentricity $\left(e_{\text {tot }}\right)$. The effective axial strengths of the column specimens $\left(P_{e}\right)$ were calculated by considering the effects of 


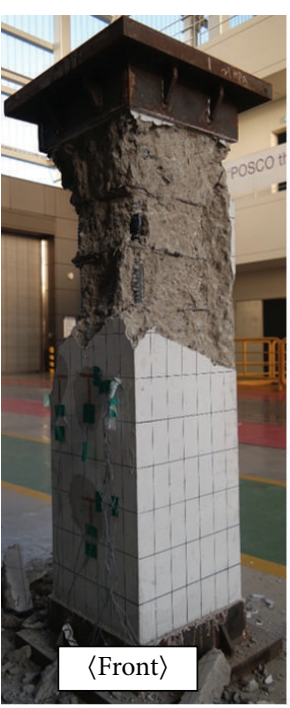

(a) R21-S600
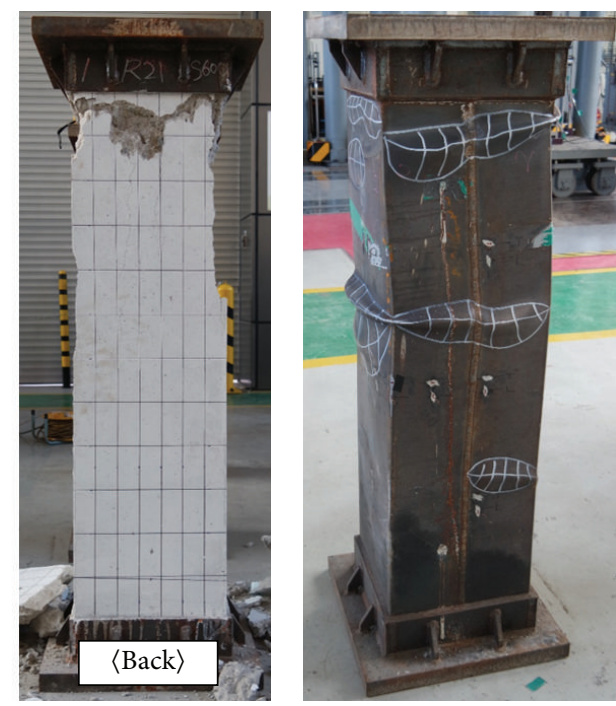

(b) P21-S600

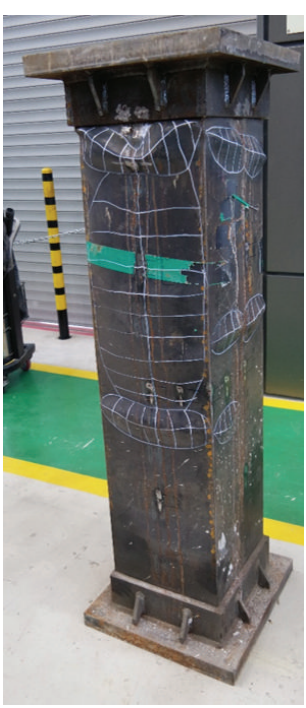

(c) P21-S600G

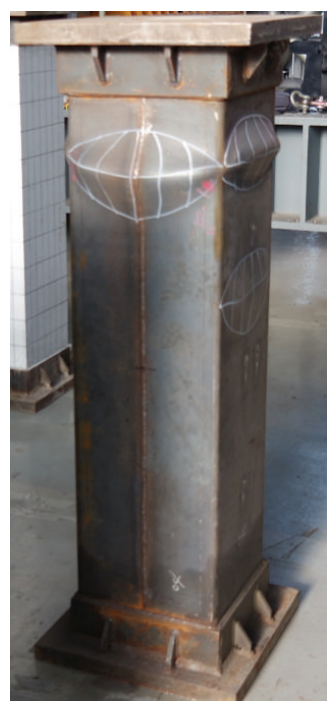

(d) CFT

FIGURE 6: Failure patterns of test specimens.

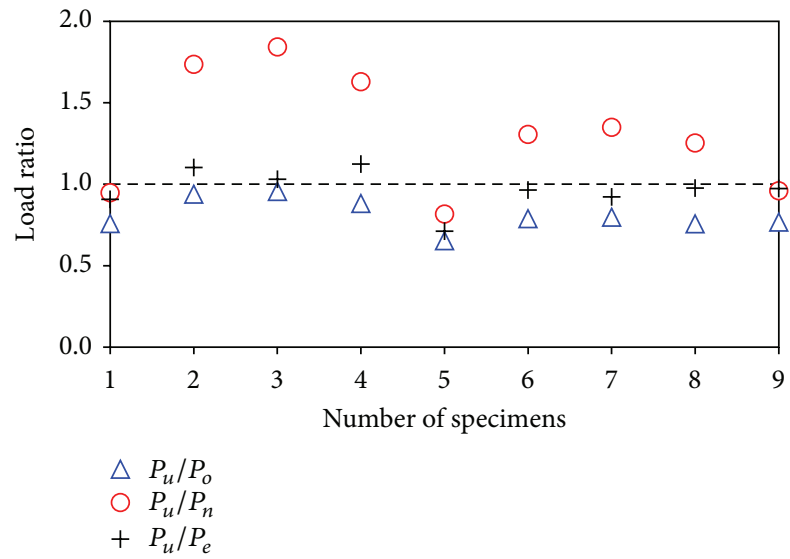

FIGURE 7: Comparisons of observed and calculated axial strengths of test specimens.

the flexural moment caused by the total eccentricity $\left(e_{\text {tot }}\right)$, and the estimated results are shown in Table 5 and Figure 7. The average of the ratios between the test results and the effective axial strengths $\left(P_{u} / P_{e}\right)$ for all the specimens was 0.97 , and the effective axial strength calculated by considering the additional eccentricity $\left(P_{e}\right)$ agreed closely with the experimental results. As mentioned above, in the ACI318-14, the nominal axial strength of RC column $\left(P_{n}\right)$ is limited to $0.8 P_{o}$, and this corresponds to the total eccentricity $\left(e_{\text {tot }}\right)$ of $35.0 \mathrm{~mm}$ according the estimation method shown in Figure 9(a), which is also equivalent to about $10.0 \%$ of the cross-sectional width (B).

As shown in Table 5 and Figure 7, the average of ratio between the nominal strengths and ultimate strength of the test specimens $\left(P_{u} / P_{n}\right)$ was 1.32 , where it is noted that the contribution of the permanent steel form was not considered in calculating the axial strengths $\left(P_{n}\right)$, as mentioned earlier.

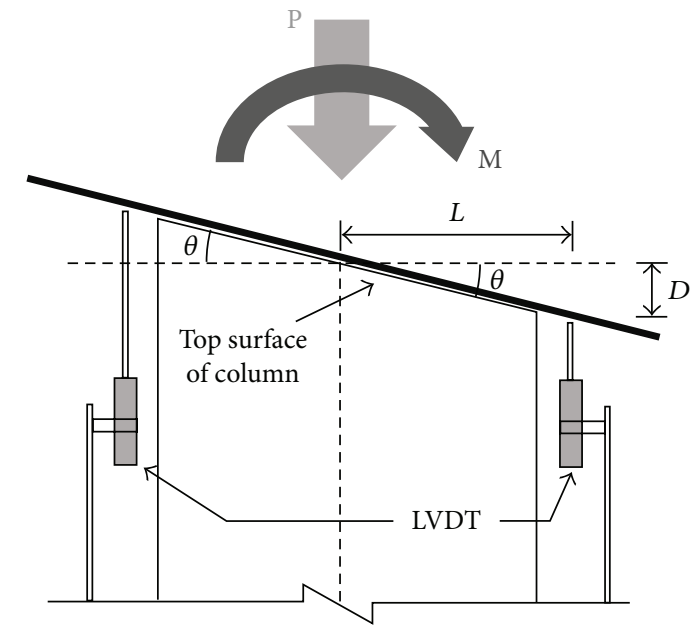

Figure 8: Axial force and flexural moment induced by minimum eccentricity.

It is, therefore, expected that a sufficient margin of structural safety can be secured when the existing RC design equation is applied to the column members fabricated by the PPSFRC method proposed in this study.

\section{Conclusions}

In this study, the prefabricated permanent steel form integrated with reinforcing cage (PPSFRC) was developed, and the structural performance of the reinforced concrete column specimens fabricated by the PPSFRC method was investigated through the axial compression testing on a total of the nine specimens. In addition, the applicability of the current axial strength estimation models specified in national design 


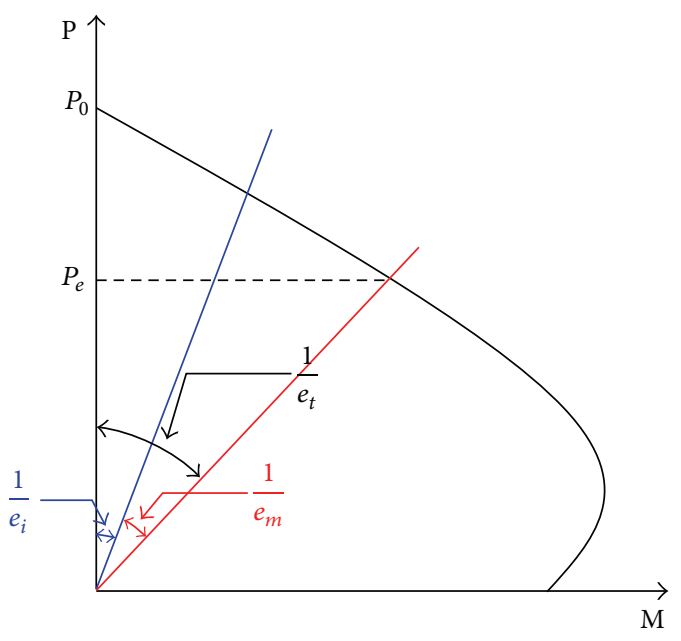

(a) Eccentricity effect in P-M relation curve

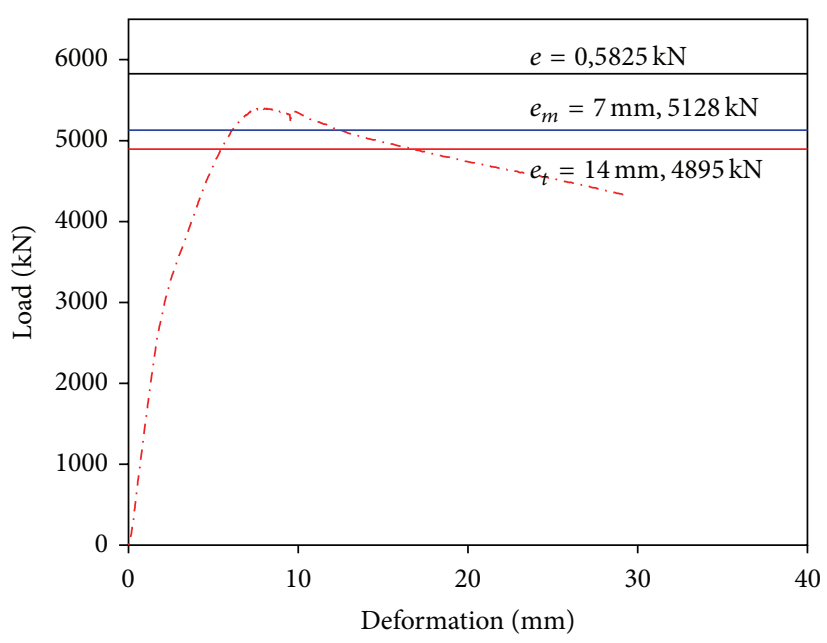

(b) Strength of P21-S600 considering eccentricity

Figure 9: P-M interaction model considering the effect of eccentricity.

codes on the PPSFRC columns was also evaluated. From this study, the following conclusions can be obtained:

(1) It was observed that local buckling was well controlled, not concentrated at a section, by the steel channels and angles provided in the longitudinal and transverse direction of the PPSFRC columns, and the PPSFRC columns showed more ductile behavioral characteristics compared to the conventional CFT column.

(2) The axial strength of the cross section without a consideration of the initial imperfection and the minimum eccentricity of applied loads overestimated the measured axial strengths of the specimens $\left(P_{u}\right)$ by up to $25 \%$, and the effective axial strength of the column $\left(P_{e}\right)$ considering the influence of the minimum eccentricity and the initial imperfection provided a good analysis accuracy.

(3) It turned out that $B / 10$ considered as the minimum eccentricity of the column in ACI318-14 was very close to the total eccentricity $\left(e_{\text {tot }}\right)$, which is a sum of the loading eccentricity measured in this study $\left(e_{m}\right)$ and the eccentricity induced by the initial imperfection $\left(e_{i}\right)$.

(4) The PPSFRC column specimens $\left(P_{u}\right)$ showed enhanced axial strengths $\left(P_{n}\right)$ with sufficient reserved strengths by more than $30 \%$, compared to the design strength of the conventional RC column. Therefore, it is expected that the PPSFRC columns can be designed with a sufficient margin of safety by the conventional RC design method.

\section{Competing Interests}

The authors declare that there is no conflict of interests regarding the publication of this paper.

\section{Acknowledgments}

This research was supported by the Research Grant from University of Seoul through the Korea Agency for Infrastructure Technology Advancement funded by the Ministry of Land, Infrastructure and Transport of the Korean government (Project no. 15TBIP-C092932-02).

\section{References}

[1] A. Mwafy, N. Hussain, and K. El-Sawy, "Seismic performance and cost-effectiveness of high-rise buildings with increasing concrete strength," The Structural Design of Tall and Special Buildings, vol. 24, no. 4, pp. 257-279, 2015.

[2] H. Sezen and M. Shamsai, "High-strength concrete columns reinforced with prefabricated cage system," Journal of Structural Engineering, vol. 134, no. 5, pp. 750-757, 2008.

[3] M. Shamsai, E. Whitlatch, and H. Sezen, "Economic evaluation of reinforced concrete structures with columns reinforced with prefabricated cage system," Journal of Construction Engineering and Management, vol. 133, no. 11, pp. 864-870, 2007.

[4] T. T. Lie and T. D. Lin, "Fire performance of steel reinforced concrete columns," Journal of Structural Engineering, vol. 141, no. 4, 2014.

[5] T. T. Lie and T. D. Lin, "Influence of restraint on fire performance of reinforced concrete columns," Fire Safety Science, vol. 1, pp. 291-300, 1986.

[6] M. Johansson and K. Gylltoft, "Mechanical behavior of circular steel-concrete composite stub columns," Journal of Structural Engineering, vol. 128, no. 8, pp. 1073-1081, 2002.

[7] J. Liu, X. Wang, and S. Zhang, "Behavior of square tubed reinforced-concrete short columns subjected to eccentric compression," Thin-Walled Structures, vol. 91, pp. 108-115, 2015.

[8] X. Zhou and J. Liu, "Seismic behavior and strength of tubed steel reinforced concrete (SRC) short columns," Journal of Constructional Steel Research, vol. 66, no. 7, pp. 885-896, 2010.

[9] X. Zhou, B. Yan, and J. Liu, "Behavior of square tubed steel reinforced-concrete (SRC) columns under eccentric compression," Thin-Walled Structures, vol. 91, pp. 129-138, 2015. 
[10] S.-J. Lee, D. H. Lee, K. S. Kim, J.-Y. Oh, M.-K. Park, and I.-S. Yang, "Seismic performances of RC columns reinforced with screw ribbed reinforcements connected by mechanical splice," Computers and Concrete, vol. 12, no. 2, pp. 131-149, 2013.

[11] AISC-LRFD, Load and Resistance Factor Design Specification for Structural Steel Buildings, AISC, Chicago, Ill, USA, 1999.

[12] Eurocode4, Design of steel and composite structures, Part 1-1 General rules and rules for buildings, 1994.

[13] KBC, Korean Building Code, Architectural Institute of Korea, Seoul, Republic of Korea, 2009.

[14] ACI-318, Building Code Requirements for Reinforced Concrete, ACI, Detroit, Mich, USA, 2014.

[15] J. G. MacGregor, J. K. Wight, S. Teng, and P. Irawan, Reinforced Concrete: Mechanics and Design, Prentice Hall, Upper Saddle River, NJ, USA, 1997. 

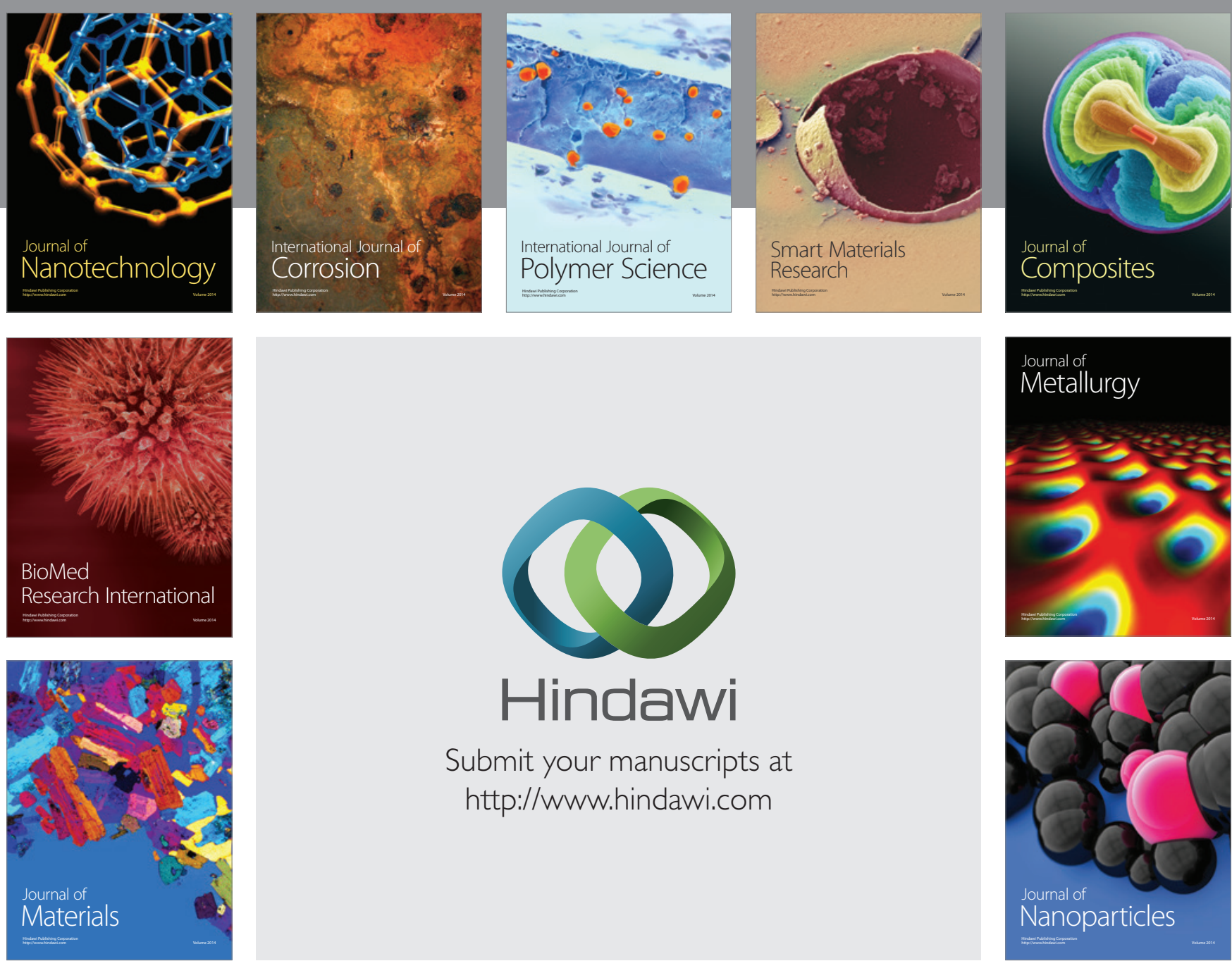

\section{Hindawi}

Submit your manuscripts at

http://www.hindawi.com

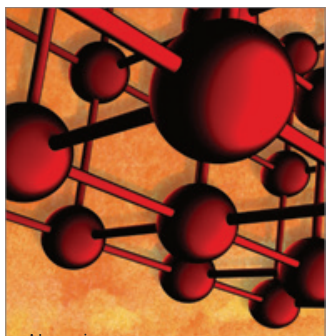

Materials Science and Engineering
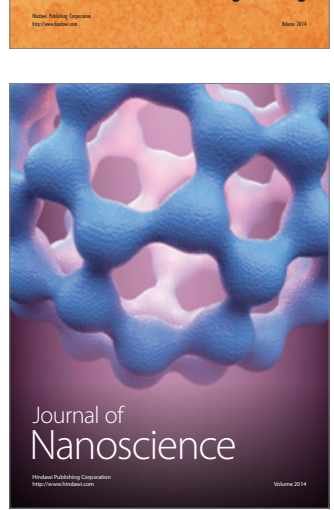
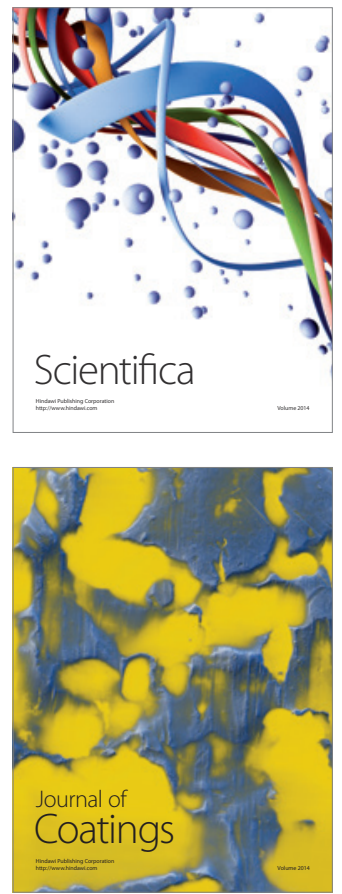
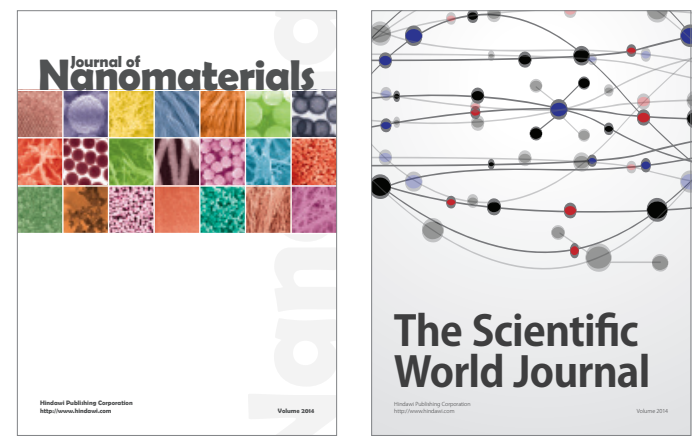

The Scientific World Journal
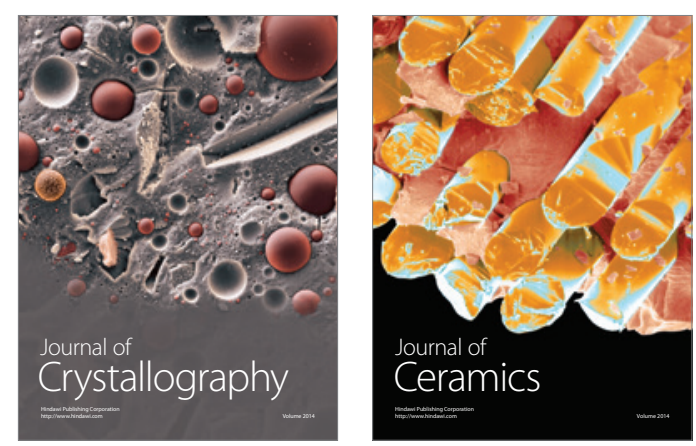
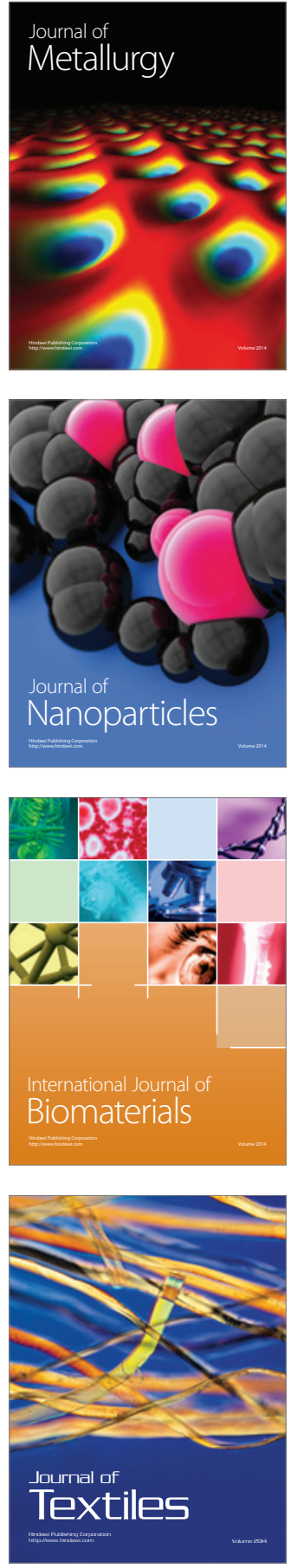